International Journal of Physical Sciences and Engineering
Available online at http://sciencescholar.us/journal/index.php/ijpse
Vol. 3 No. 3, December 2019, pages: 7 20
e-ISSN : 2550-6943, p-ISSN : 2550-6951
https://doi.org/10.29332/ijpse.v3n3.353

\title{
Analysis of working conditions to which the triaduct is subjected in Roca Fuerte route - Manta
}

\author{
Ana Valeria Palacios Mendoza a , Carlos Gustavo Villacreses Viteri ${ }^{b}$, Edgar Antonio Menendez \\ Menendez ${ }^{c}$
}

Article history: Received 18 April 2019, Accepted: 30 August 2019, Published: 02 November 2019

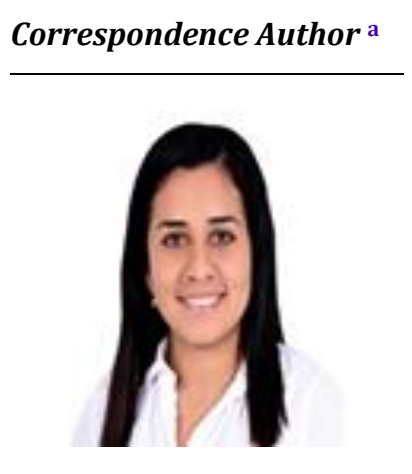

Keywords

bridge;

sewer;

triaduct;

working conditions;

hydraulic flow;

\begin{abstract}
In the work, the working conditions to which the triaduct is located in the Rocafuerte - Manta road are analyzed, with vehicle service conditions similar to those of a bridge since they share the same scenario. Despite their similarities, these two civil works, bridges and sewers, have a different structural behavior and design; The bridge sits on supports that are placed from end to end or in an intermediate way, while the sewer has a base that covers the entire area on which it will settle under a concept similar to that of a shoe or foundation slab, it also has with walls on its sides fulfilling the function of walls, which gives a drawer shape to this structure and hence its name. The working conditions of the aforementioned triaduct are analyzed, which are caused by vehicular traffic, earth thrusts, hydraulic flow, seismic load and a filler load that could be placed on the upper road slab that is not present on a bridge and corresponds to a dead load distributed because of the filling.
\end{abstract}

e-ISSN: 2550-6943, p-ISSN: 2550-6951 ๑Copyright 2019. The Author. SS Journals Published by Universidad Técnica de Manabí. This is an open-access article under the CC BY-SA 4.0 license (https://creativecommons.org/licenses/by-sa/4.0/) All rights reserved.

\section{Contents}

Abstract 7

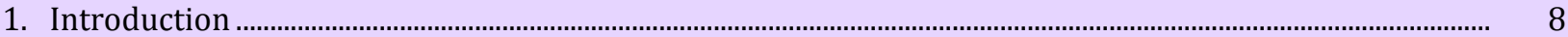

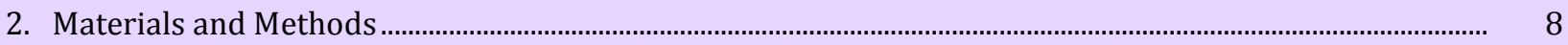

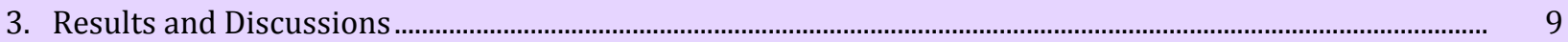

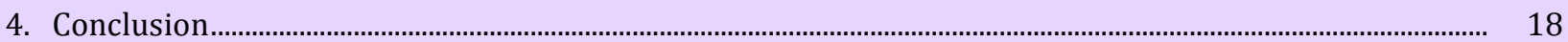

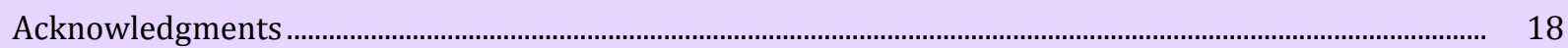

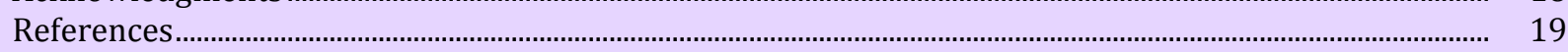

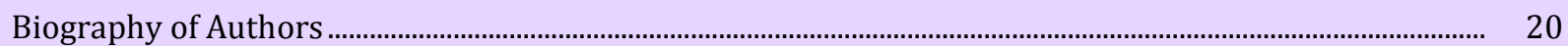

a Universidad Técnica de Manabí, Portoviejo, Ecuador

b Universidad Técnica de Manabí, Portoviejo, Ecuador

c Universidad Técnica de Manabí, Portoviejo, Ecuador 


\section{Introduction}

Over the years the need to build roads and open steps through inaccessible places have led the human being to apply to engineer, bridges are civil works used to save geographical accidents (Yepes, 2017), these geographical accidents can be rivers, canyons, valleys, among others.

There are bridges of all shapes and sizes, but they all play a key role in bringing communities together and improving everyday life, contributing to the social and economic development of society (Benjumea et al., 2010).

In the construction of communication routes, sewers are fundamental structures for the effective control and management of water, being its main objective to drive the water that is generated by the effects of runoff resulting from rainfall, or other anthropogenic causes, in order to be able to download to a ravine or take its natural course to drain to a collector course or the sea (Lituma, 2014).

In the accident $20+033.61$ of the Rocafuerte - Manta road where the triaduct is located, the presence of clay and expansive soils, are reasons why there are constant landslides, due to seismic causes and water ingress in the soils that, aggravated by their deconsolidation, generate the effects noted above. The objective of the work is to determine the working conditions to which the triaduct is subjected to the Rocafuerte Manta road.

\section{Materials and Methods}

The investigative procedure is developed under the conditions of an exploratory investigation since it focuses on analyzing and investigating specific aspects of the analysis of the working conditions to which the Rocafuerte - Manta triaduct is subjected. Figure 1 shows the micro-location of this work.

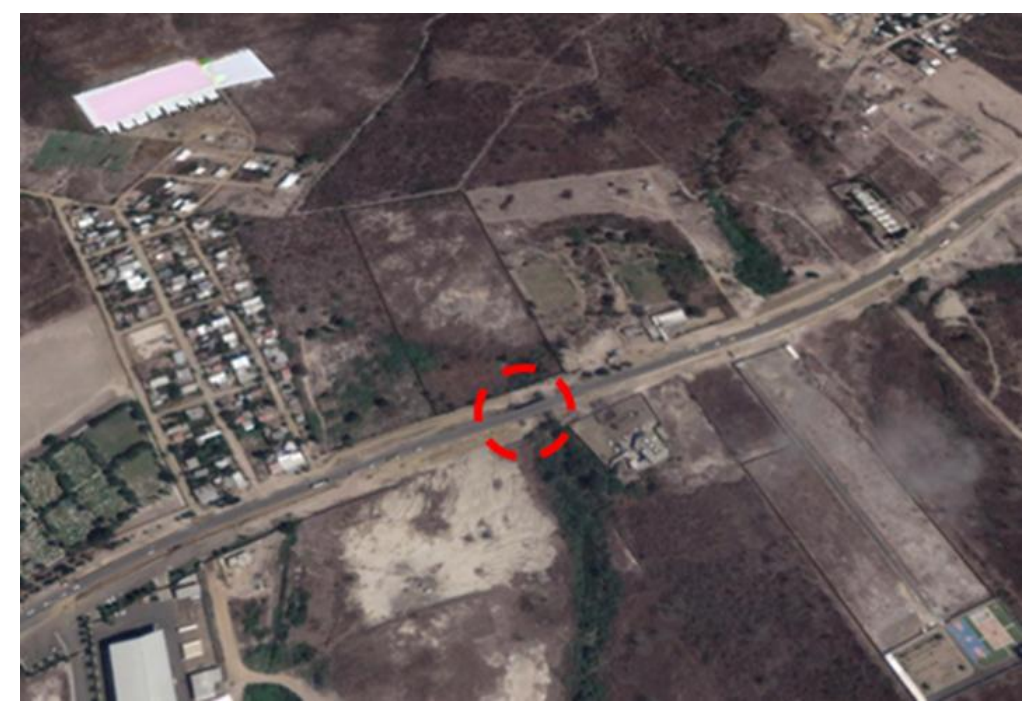

Figure 1. Micro location of the triaduct on the Roca Fuerte - Manta road Source: Prepared by Google Maps, 539344.06 m E; 9892649.11 m S.carry

To out the research, a group of theoretical and empirical methods was put into practice. Within the theoretical methods can be noted: historical-logical, for the study of the background of the research problem; documentary analysis, to evaluate the studies and research previously carried out on the Roca Fuerte - Manta triaduct; analysis-synthesis, to analyze the problematic situation according to the documentary diagnosis and establish possible solutions; induction-deduction, for the study of all aspects related to the current regulations governing the design of Bridges in Ecuador to establish general considerations that allow conclusions. 


\section{Results and Discussions}

Hydraulic drainage consists of evacuating the excess water that can accumulate on the surface of the land due to intense and frequent rains and develops on flat and irregular topographies formed by different soils (Castelló, 2016).

The bridges are presented as structures that allow the operation of works of very different purposes, allowing them to save equally varied geographical accidents, whether natural or artificial (Santos, 2015).

The sewers are closed ducts that are constructed transverse to an embankment and below it, in order to superficially conduct the rainwater from the ditches and against ditches to natural channels, eliminating the danger of damage and traffic interruptions.

Sewers are minor structures, although they may become works of some importance, according to specific circumstances, they are generally used as passages through embankments (García \& Lorenzo, 2011).

There are noticeable differences in terms of the visual in terms of a bridge or a sewer (Aquini \& Hernández, 2004), but apart from that also with regard to its function. The optimal location of the sewers depends on their alignment and slope, which is achieved by projecting said structure following the alignment and slope of the natural channel (Guillen, 2017). It also affects the transport capacity of suspended materials and bottom trawling.

Vente Chow et al., (1994), in his book "Applied Hydrology" states that hydrological phenomena are extremely complex and may never be fully understood. The objective of the hydrological system is to study the operation of water and predict its output the inputs and outputs of the flow can be expressed as time functions I $(t)$ and $Q(t)$ respectively where $t$ the time range belongs. The hydrographic basin is the land space limited by the segment formed by water divorces in the highest parts of the mountains, hillsides, and hills. The river basins have different characteristics: the perimeter, the area, length of the riverbed, vegetation cover, soil type, slope, soil, drainage, and topography and point interest.

There several methods to calculate the flow in watersheds rational method, abstractions method and the method of unit hydrograph, among others.

The method Raci It is based on the fact that the flow generated by a basin contributing to the main channel, which is influenced by the area of the basin, by the precipitation given in the basin, by the time of concentration, by the intensity of the rain, by the type of soil and its coverage. It has limitations, in very large basins the area affects the intensity and as it really is not constant throughout the basin intensifies it. It can only be used for basins of areas smaller than $5 \mathrm{~km} 2$.

It was considered that according to the general doctrine respect to bridge hydraulics, for a length of 15 meters in the service of a natural channel, a single-light bridge should have been built because of precautionary flows and that floating garbage circulate without difficulty under the bridge.

It is presumed that the competent authority that made the decision to arrange the design and construction of this triple sewer battery, estimated that floating flows and garbage could circulate under the sewer due to an analysis of the contributing area.

In the field observation downstream of the sewer outlet at a distance of approximately twenty meters, a wall with a concrete and brick base that forms a perimeter enclosure is built perpendicular to the flow of water and parallel to the road. same that in its inferior part and aligned with the flow of the sewer only maintains a circular tube, whose diameter is of $1500 \mathrm{~mm}$ that serves as a sewage drainage channel towards the particular land, with the turn of the channel to its left being the flow of water with an area of buildings for housing use.

In the last significant rainfall that occurred in the month of March of this year specifically on March 7, 2019 , the basin contributed an important amount of flow of $0.85 \mathrm{~m} 3 / \mathrm{s}$ of water with an $80 \mathrm{~cm}$ strap which caused affectations in the aforementioned homes. Figure 2 shows a panoramic view of the triaduct on March 7, 2019.

Mendoza, A. V. P., Viteri, C. G. V., \& Menendez, E. A. M. (2019). Analysis of working conditions to which the triaduct is subjected in Roca Fuerte route - Manta. International Journal of Physical Sciences and Engineering, 


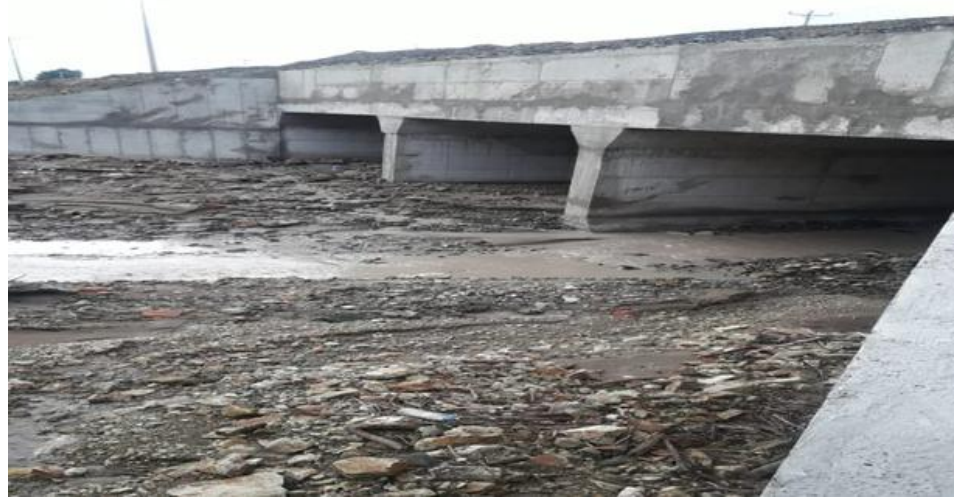

Figure 2. Triaduct studied on March 7, 2019

This is a route that connects two productive cantons in the province and links Manta with the north and south of the province of Manabí and the country through the port and industrial activity, which generates a vehicular circulation of heavy and tourist traffic with the characteristic of light heavyweights. Due to the importance of this road section, the extension of this road to six lanes is under construction. The road is cataloged first order and with heavy traffic of medium and high intensity.

The Ecuadorian State has allocated significant resources for its expansion to six lanes of vehicular traffic. Being part of this project the intervention in the triaduct under study.

The unit of measurement of traffic in a given section of road is the annual average daily traffic volume (TPDA), which is equivalent to the average daily vehicular volume corresponding to a calendar year (MTOP, 2013).

Table 1

Shows the analysis of the annual average daily traffic on the Roca Fuerte to Manta road

\begin{tabular}{|c|c|c|c|c|c|c|c|c|c|}
\hline \multicolumn{10}{|c|}{ VEHICLE CLASSIFICATION } \\
\hline \multirow[b]{3}{*}{ VEHICLE } & \multirow[b]{3}{*}{ LIGHT } & \multirow{3}{*}{$2^{\text {Bus }}$} & \multicolumn{2}{|c|}{ Two-axle } & \multicolumn{4}{|c|}{ truck Heavy truck } & \multirow[b]{3}{*}{ TPDA } \\
\hline & & & LIGHT & HALF & 3 & 4 & 5 & 6 & \\
\hline & & & & & AXES & AXES & AXES & AXES & \\
\hline Quantity & 5406 & 131 & 89 & 751 & 181 & 21 & 138 & 136 & 6853 \\
\hline$\%$ & 78.80 & 1.91 & 1.30 & 10.96 & 2.64 & 0.30 & 2.01 & 1.98 & 100.00 \\
\hline
\end{tabular}

Source: Archives of the Ministry of Public Works

\section{Structural analysis}

The purpose of the work is to perform a technical analysis of the structural-functional conditions of the triple sewer built in the $20+033.61$ area of the Rocafuerte - Manta road.

The triple drawer type sewer has three closed ducts, which consist of an upper and lower slab whose thickness is 60 centimeters, also has two exterior walls that function as a wall whose thickness is 60 centimeters.

The total length of the structure parallel to the road traffic is 17 meters, the total length transverse to the road is 32 meters. The filling of granular material on the top slab of 1.20 meters. We worked with a resistance to concrete $\mathrm{f}^{\prime} \mathrm{c}=280 \mathrm{~kg} / \mathrm{cm}^{\wedge} 2$, and the creep of steel Fy $=4200 \mathrm{~kg} / \mathrm{cm}^{\wedge} 2$. Figure 3 shows the structure of the Roca Fuerte Manta triaduct. 


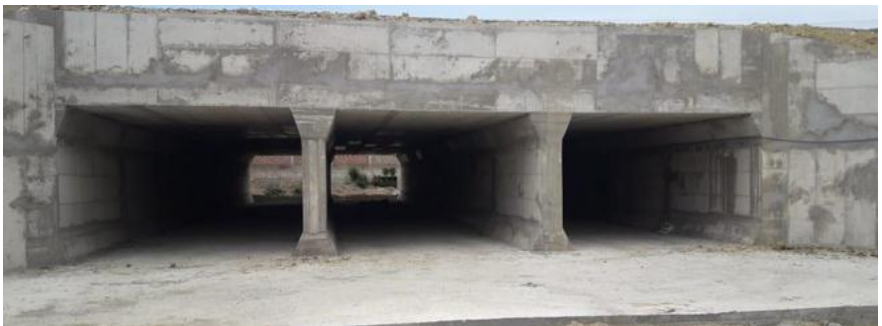

Figure 3. Structural sample of the Manta - Rocafuerte road triaduct

Source: Photo taken by the author of the work on February 10, 2019

For the analysis, the Ecuadorian road standard NEVI-12 and the ASTTHO LRFD standard of 2014 have been specifically used, which is an American regulation that is used in several countries for the construction of sewers and bridges, on which we have based the aforementioned technical regulations of the LRFD type, using the load combinations there are expressed to determine the technical goodness of the work.

In the analysis we have used the load requests of type HL93, which consists of the combination of loads of a design truck, a design tandem, and a design rail, as determined by the ASTTHO LRFD (2014) standard, we proceeded to classify the different loads that cause solicitations according to the table (Rodríguez, 2014).

For the live load, we use the HL93, for the dead load the filling of a thickness of approximately 1.20 meters of granular filling plus the weight of the structure, reinforced concrete and the 4-inch thick asphalt rolling folder, according to the specifications AASHTO for the design of bridges by the LRFD method (2014).

\section{Calculation report}

Work: Triaduct on the Rocafuerte - Manta track, excise $20+033.61$

Proposed Model:

The total longitudinal length of the track: $17 \mathrm{~m}$

Total length transverse to the track: $32 \mathrm{~m}$

Fill Height: $1.20 \mathrm{~m}$

The resistance of the concrete $\left(\mathrm{f}^{\prime} \mathrm{c}\right): 280 \mathrm{~kg} /\left[\mathrm{cm} \rrbracket^{\wedge} 2\right.$

Steel creep (Fy): $4200 \mathrm{~kg} /\left[\mathrm{cm} \rrbracket^{\wedge} 2\right.$

The specific weight of the granular filling soil: $1800 \mathrm{~kg} / \mathrm{m}^{\wedge} 3$. Figure 4 shows the modeling of the triaduct and its dimensions.

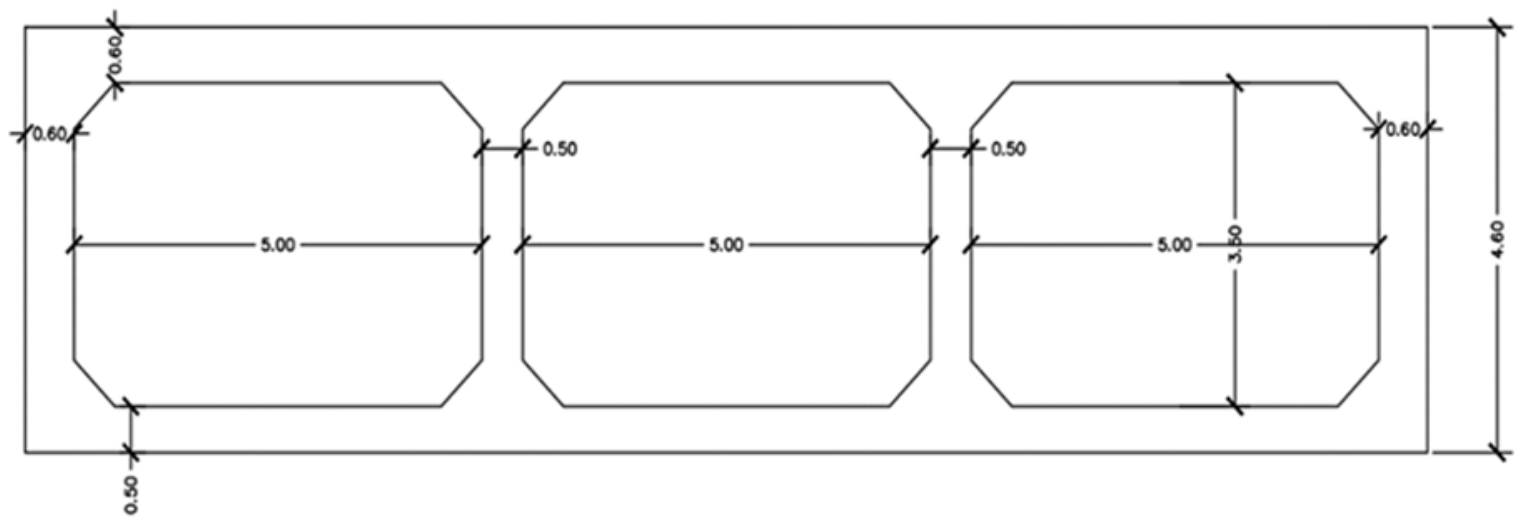

Figure 4. Triaduct modeling and its dimensions

Source: Author's own elaboration in the SAP 2000 software

Mendoza, A. V. P., Viteri, C. G. V., \& Menendez, E. A. M. (2019). Analysis of working conditions to which the triaduct is subjected in Roca Fuerte route - Manta. International Journal of Physical Sciences and Engineering, 3(3), 7-14. https://doi.org/10.29332/ijpse.v3n3.353 
Loads and load factors

The calculation will be carried out on a standard basis, and the method of the AASHTO - LRFD standard, and the most unfavorable condition will be taken for the design.

\section{Load combinations Standard Method}

The LRFD takes the nature of the charges one by one and proposes factors for each of them. In this way, it creates the design combinations, where the usual loads are increased depending on its field of action and its probability of occurrence in the life of the structure. Then, it is possible to involve each of the loads involved in the analysis in a unitary manner, as shown in equation 1.

$$
M \operatorname{Mr}_{L R F D}=1.3(M D C+1.67(M L L+M i))
$$

Where:

MDC $\rightarrow$ dead load values, this filling being the structure's own weight

$\mathrm{MLL} \rightarrow$ Corresponding to the live load of the truck

$\mathrm{Mi} \rightarrow$ Impact generated load

Remarks: If the depth of the filling is less than $600 \mathrm{~mm}$, the effect of the filling on the distribution of the overload. If the depth of the filling is greater than $600 \mathrm{~mm}$, it can be considered that the wheel loads are evenly distributed in a rectangular area.

For sewers of a single section the effects of overload can be neglected if the depth of the filling is greater than $2400 \mathrm{~mm}$ and greater than the length of the section, for sewers of multiple sections these effects can be neglected if the depth of the filling is greater than the distance between the faces of the extreme walls.

\section{Buried}

Components the dynamic load component for sewers and other covered buried structures: in percentage, it should be taken as shown in equation 2 .

$$
I M=33\left(1.0-4.1 * 10^{-1} S D\right) \geq 0 \%
$$

Where:

$\mathrm{DE} \rightarrow$ En Minimum depth of the earth cover on the millimeter structure.

\section{Combinations of loads and load factors}

The AASHTO proposes more types of loads, however, these are not relevant, as they do not apply in the case of sewers. Thus, the following charges were used, with their respective nomenclatures (taken from AASHTO LRFD 3.4.1.1 and 3.4.1.2). Table 2 shows the combinations of loads and load factors.

Table 2

Combinations of loads and load factors load

\begin{tabular}{lll}
\hline \multirow{2}{*}{ Type Load } & \multicolumn{2}{c}{ Factor } \\
\cline { 2 - 3 } & Maximum & Minimum \\
\hline$D C:$ Element and accessories & 1.25 & 0.90 \\
$D D:$ Negative friction (downdrag ) & 1.80 & 0.45 \\
$D W:$ Bearing surfaces and facilities for public services & 1.50 & 0.65 \\
EH: Horizontal ground thrust & & \\
- Active & 1.50 & 0.90 \\
- At rest & 1.35 & 0.90 \\
EL: Residual stresses Mounting & 1.00 & 1.00 \\
EV: Vertical floor thrust & 1.00 & \\
- Global stability & 1,35 & $\mathrm{~N} / \mathrm{A}$ \\
- Support walls and stirrups & 1.30 & 1.00 \\
- Rigid buried structure & 1.35 & 0.90
\end{tabular}




\begin{tabular}{lcc}
- Rigid frames & 1.95 & 0.90 \\
- Flexible buried or other structures, except & & 0.90 \\
rectangular metal sewers sewers & & \\
- Flexible rectangular metal & 1.50 & 0.90 \\
ES: Soil overload & 1.50 & 0.75 \\
\hline
\end{tabular}

Source: Taken from the AASHTO LRFD book (2014)3.4.1-1

Table 3 shows the load factors for permanent loads.

Table 3

Load factors for permanent loads ( $\gamma p$ ) Load

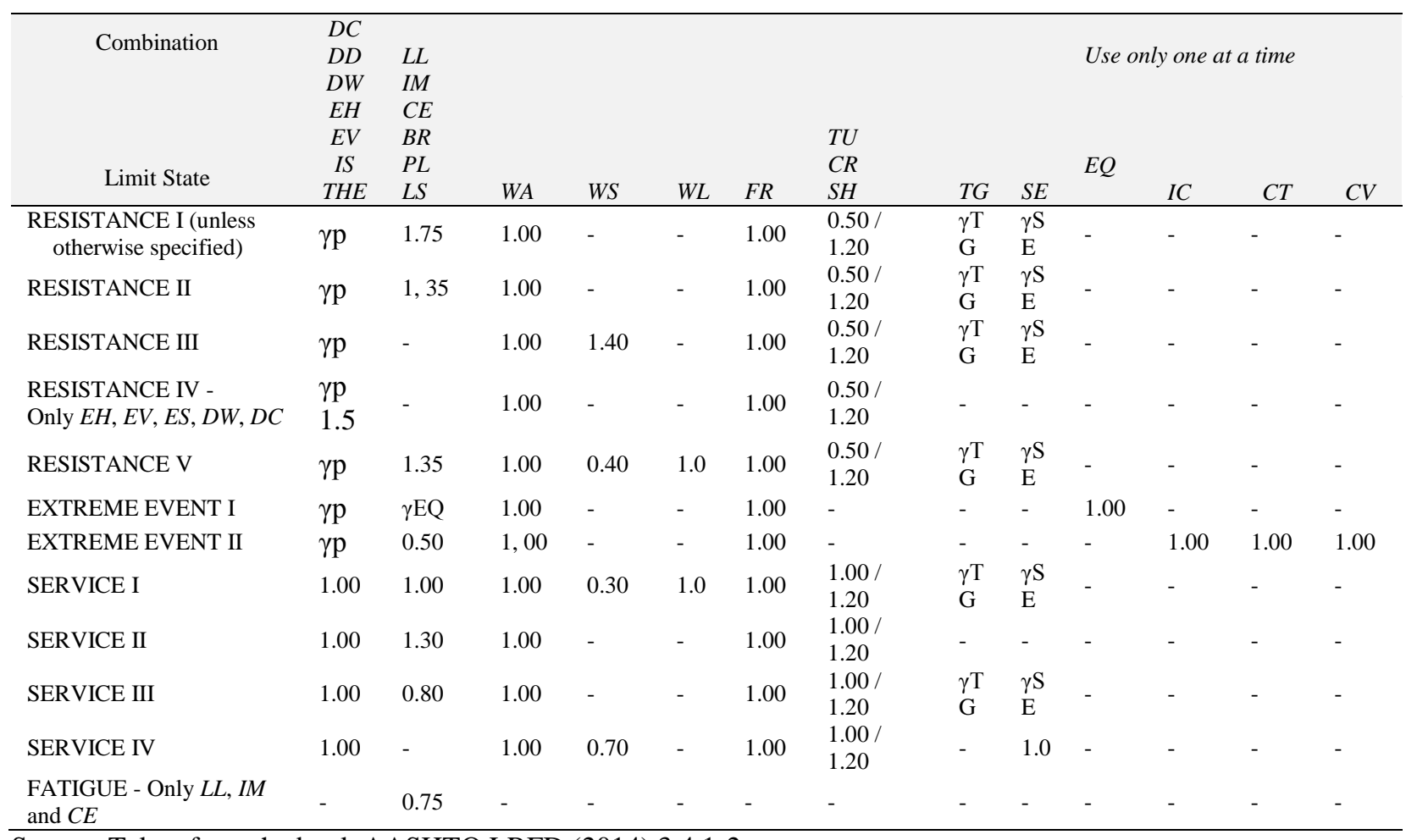

Source: Taken from the book AASHTO LRFD (2014) 3.4.1-2

Acronyms of the tables:

Table 3

Acronyms

\begin{tabular}{llllll}
\hline DC & But typical of the non-structural & IM & Increase by dynamic & FR & Friction. \\
$\rightarrow$ & components. & $\rightarrow$ & vehicle load. & $\rightarrow$ & \\
DD & Negative friction. & CE & The centrifugal force of & TU & Uniform \\
$\rightarrow$ & & $\rightarrow$ & vehicles. & $\rightarrow$ & temperature. \\
DW & But typical of bearing surfaces. & BR & The braking force of & CR & Slow creep. \\
$\rightarrow$ & & $\rightarrow$ & vehicles. & $\rightarrow$ & \\
EH & Horizontal floor thrust. & PL & Pedestrian overload. & SH & Contraction. \\
$\rightarrow$ & & $\rightarrow$ & & & \\
EV & Vertical pressure of the filling's own & LS & Live overload. & TG & Temperature \\
$\rightarrow$ & weight. & $\rightarrow$ & & $\rightarrow$ & gradient.
\end{tabular}

Mendoza, A. V. P., Viteri, C. G. V., \& Menendez, E. A. M. (2019). Analysis of working conditions to which the triaduct is subjected in Roca Fuerte route - Manta. International Journal of Physical Sciences and Engineering, 3(3), 7-14. https://doi.org/10.29332/ijpse.v3n3.353 


\begin{tabular}{|c|c|c|c|c|c|}
\hline $\mathrm{EN}$ & Overground load. & WA & Hydraulic load and & SE & Settlement. \\
\hline$\rightarrow$ & \multirow{3}{*}{$\begin{array}{l}\text { Cumulative residual tensions, } \\
\text { resulting from the construction } \\
\text { process. }\end{array}$} & $\rightarrow$ & water flow pressure. & $\rightarrow$ & \\
\hline EL & & WS & \multirow[t]{2}{*}{ Wind over the structure. } & EQ & \multirow[t]{2}{*}{ Earthquake. } \\
\hline$\rightarrow$ & & $\rightarrow$ & & $\rightarrow$ & \\
\hline LL & Over vehicular load & WL & Wind over overload. & $\mathrm{CV}$ & Collision force of a \\
\hline$\rightarrow$ & & $\rightarrow$ & & & vessel. \\
\hline
\end{tabular}

Once the loads that are used in the design are obtained, the combinations found in Table 2, "Combinations of load and load factors," are prepared, from which only the combinations containing the loads described above are chosen, since the remaining ones are not applicable for the case analyzed. The selection criteria for the load combinations used are:

The resistance I $\rightarrow$ Basic load combination representing the normal vehicular use of the bridge, without wind.

Resistance $\mathrm{II} \rightarrow$ A combination of loads that represents the use of the bridge by vehicles of special designs specified by the owner, restricted circulation vehicles, or both, without wind.

Resistance III $\rightarrow$ Combination of loads representing the bridge exposed to winds of speeds greater than 90 $\mathrm{km} / \mathrm{h}$.

Resistance IV $\rightarrow$ A combination of loads that represents very high relations between the stresses caused by permanent loads and those caused by overloads.

Resistance $\mathrm{V} \rightarrow$ Combination of loads representing the use of the bridge by normal vehicles with a wind speed of $90 \mathrm{~km} / \mathrm{h}$.

The extreme event I $\rightarrow$ Combination of loads that includes earthquakes.

Extreme event II $\rightarrow$ A combination of loads that includes ice loading, the collision of ships and vehicles and certain hydraulic events with a reduced overload different from that which is part of the vehicle collision load.

Service I $\rightarrow$ Combination of loads that represents the normal operation of the bridge with a wind of $90 \mathrm{~km}$ / $\mathrm{h}$, taking all the loads to their nominal values.

Service II $\rightarrow$ Combination of loads whose intention is to control the creep of steel structures and the slippage caused by vehicular overload in critical slip connections.

Service III $\rightarrow$ Combination of loads related exclusively to traction in prestressed concrete superstructures, whose objective is to control the figuration.

Service IV $\rightarrow$ A combination of loads related exclusively to traction in prestressed concrete substructures, whose objective is to control the figuration.

Fatigue $\rightarrow$ Combination of fatigue and fracture loads that are related to repetitive vehicle gravitational overload and dynamic responses under a single design truck with wheelbase.

\section{Load combinations}

Design path weights and the separation between the two 145,000 N axes should be varied between 4300 and $9000 \mathrm{~mm}$ to produce extreme stresses they will be as specified in figure 5 . 


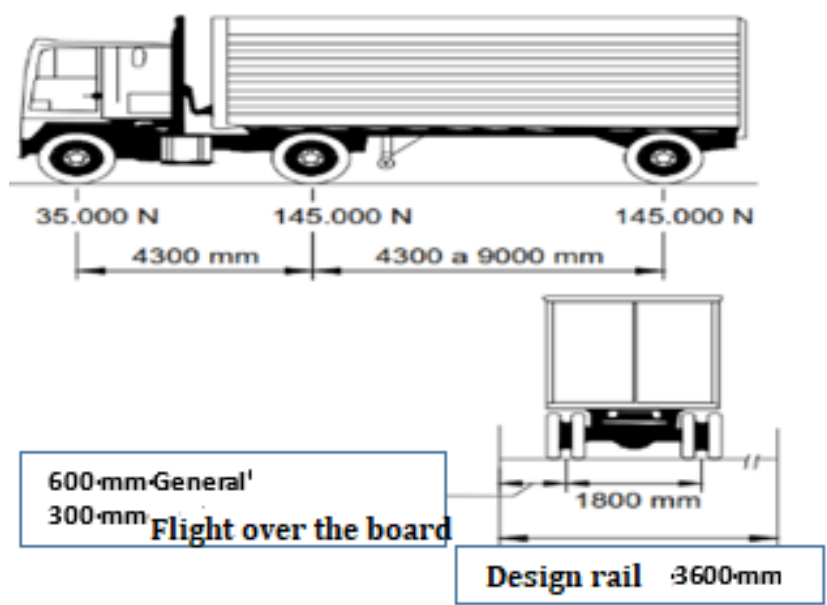

Figure 5. For Extreme Solutions

Source: Book has taken (AASHTO LRFD, 2014)

Design design, tandem The tandem will consist of a pair of $110,000 \mathrm{~N}$ axes with a $1200 \mathrm{~mm}$ spacing. The transverse separation of the wheels should be taken as $1800 \mathrm{~mm}$. Design rail loads The load will consist of a load of $9.3 \mathrm{~N} / \mathrm{mm}$, evenly distributed in the longitudinal direction. Transversally the load of the designed rail will be assumed uniformly distributed over a width of $3000 \mathrm{~mm}$. Requests due to the loading of the design lane will not be subject to a dynamic load increase.

For the calculation of the last moment with the LRFD method (M/or)]_LRFD) Equation, 3 is used. In the application of table 2 .

$$
\operatorname{Mor}_{L R F D}=1.25 D C+1.75(L L+I M)
$$

Where:

$\mathrm{DC} \rightarrow$ Own weight of the structural elements and non-structural accessories.

$\mathrm{DW} \rightarrow$ own weight of the asphalt surface and granular filling of the upper slab of the triaduct.

$\mathrm{LL} \rightarrow$ corresponding to the vehicle overload

After applying the loads to the structure in a calculation software, corresponding to the HL-93 solicitations, the results of the generated moments are obtained. Figure 6 shows the moments generated by the load combinations of the standard design Source: Author's own elaboration in the SAP 2000 software
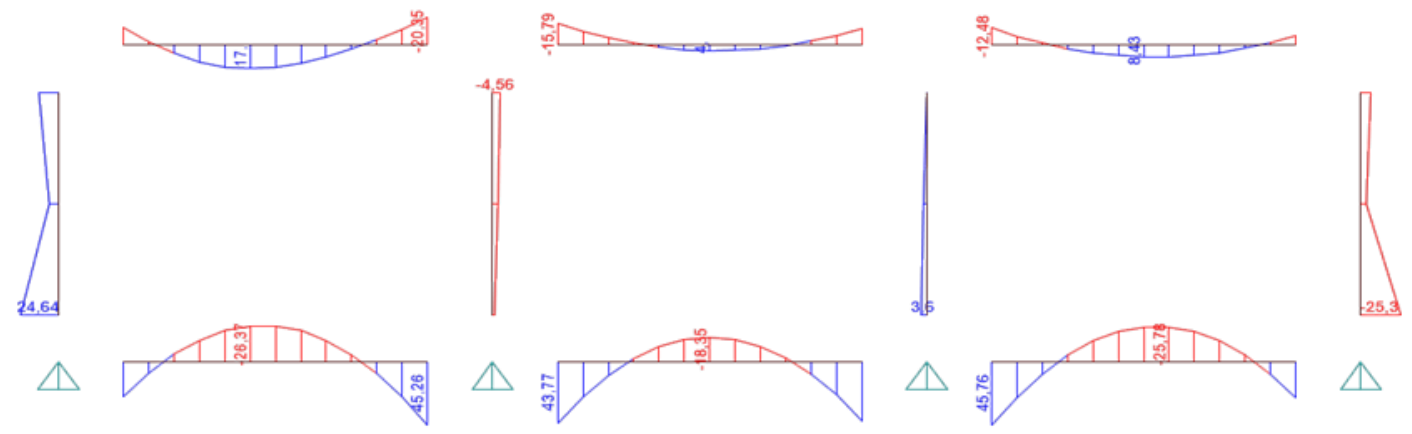

Figure 6. Moments Generated by the load combinations of the standard design Source: Author's own elaboration in the SAP 2000 software.

Mendoza, A. V. P., Viteri, C. G. V., \& Menendez, E. A. M. (2019). Analysis of working conditions to which the triaduct is subjected in Roca Fuerte route - Manta. International Journal of Physical Sciences and Engineering, 3(3), 7-14. https://doi.org/10.29332/ijpse.v3n3.353 
Figure 7 shows the moments generated by the load combinations of the AASTHO-LRFD standard design.
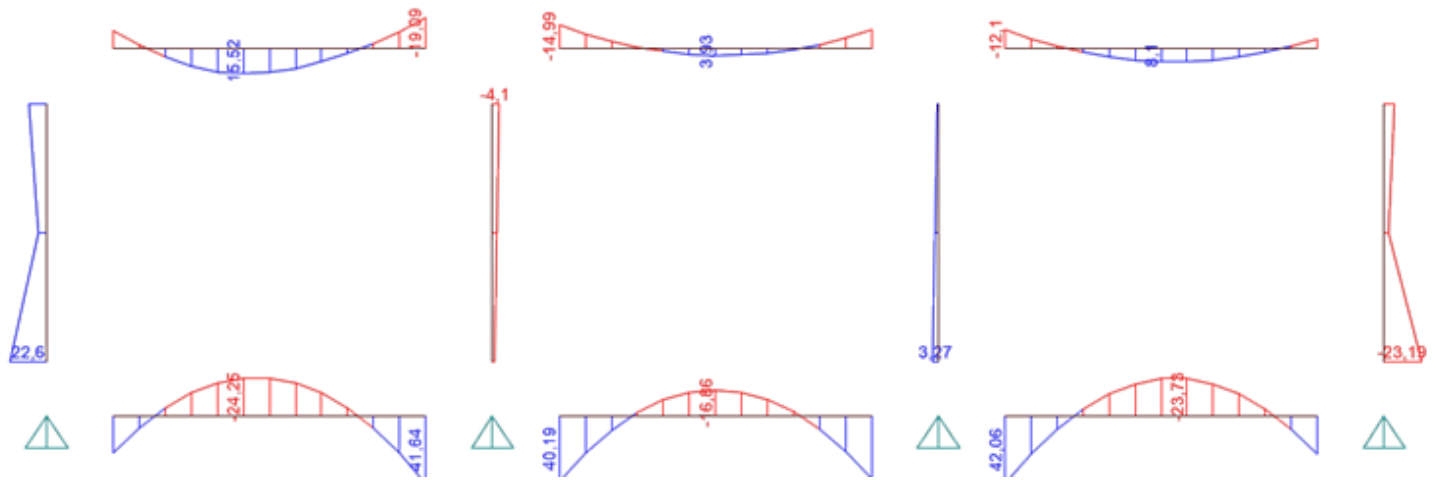

Figure 7. Moments generated by the load combinations of the AASHTO - LRFD standard design Source: Author's own elaboration in SAP 2000 software.

The most critical conditions are those presented under the combinations of the standard design, these being the most recommended for carrying out the design.

Maximum moments, amounts and steel areas

Table 4 shows a summary of the required steel areas.

Table 4

Summary of required steel areas

\begin{tabular}{|c|c|c|c|c|c|c|}
\hline Structures & $\begin{array}{l}\text { Moments } \\
(\mathrm{Tm})\end{array}$ & $\begin{array}{l}\mathrm{B} \\
(\mathrm{cm})\end{array}$ & $\begin{array}{l}\mathrm{D} \\
(\mathrm{cm})\end{array}$ & $\rho$ & $\begin{array}{l}\rho \\
0\end{array}$ & $\begin{array}{l}\text { As } \\
\left(\mathrm{cm}^{2}\right)\end{array}$ \\
\hline \multirow{6}{*}{ Upper } & 20.35 & 100.00 & 55.00 & slab0.001809 & 0.003300 & 18.150 \\
\hline & 17, & & & & & 00100.00 \\
\hline & & & & & & 55.00 \\
\hline & & & & & & 0.001507 \\
\hline & & & & & & 0.003300 \\
\hline & & & & & & 18.150 \\
\hline
\end{tabular}

bottom slab

26.37

100.00

45.00

0.003557

0.003557

16.005

45.26

100.00

Walls Lateral $\quad 25.30 \quad 100.00$

Central walls $\quad 4.56 \quad 100.00$

Source: Own elaboration

Description of the acronyms of the table

$(\mathrm{t}-\mathrm{m}) \rightarrow$ Tons per meter. $\quad \rho \rightarrow \quad$ Calculated amount.

$\mathrm{b}(\mathrm{cm}) \rightarrow \quad$ Slab width $(100 \mathrm{~mm}) . \quad \rho 0 \rightarrow$ Minimum amount.

$\mathrm{d}(\mathrm{cm}) \rightarrow \quad$ Cant of the slab or walls. $\quad$ As $(\mathrm{cm} 2) \rightarrow$ Steel area.

With the information about the structural design of the triaduct, an approximate estimate of the area of steel that was put into work could be made, which can be seen in figure 7 . 


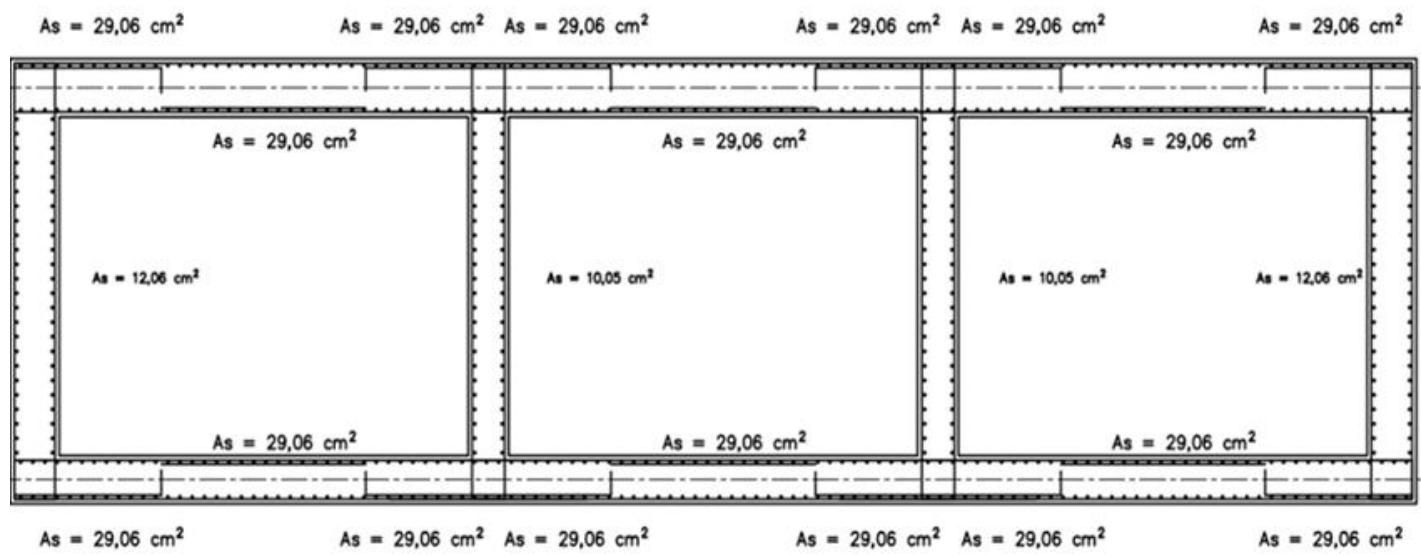

Figure 7. Distribution of steel in the structural elements of the triaduct

Steel areas placed on site

Table 5 shows the summary of steel areas placed on site.

Table 5

Summary of steel areas placed on site

\begin{tabular}{lllllc}
\hline Structure & $\mathrm{b}(\mathrm{cm})$ & $\mathrm{d}(\mathrm{cm})$ & Minimum & $\begin{array}{l}\text { Reinforcement } \\
\text { steel }\end{array}$ & As $\left(\mathrm{cm}^{2}\right)$ \\
\hline Upper & 100.00 & 55.00 & slab5 $\omega 16 \mathrm{~mm}$ & $5 \omega 22 \mathrm{~mm}$ & 29.060 \\
& 100.00 & 55.00 & $5 \omega 16 \mathrm{~mm}$ & $5 \omega 22 \mathrm{~mm}$ & 29.060 \\
lower slab & 100.00 & 45.00 & $5 \omega 16 \mathrm{~mm}$ & $5 \omega 22 \mathrm{~mm}$ & 29.060 \\
side walls & 100.00 & 45.00 & $5 \omega 16 \mathrm{~mm}$ & $5 \omega 22 \mathrm{~mm}$ & 29.060 \\
central walls & 100,00 & 55,00 & $5 \omega 16 \mathrm{~mm}$ & - & 12.060 \\
\hline
\end{tabular}

Based on the steel areas obtained, corroboration of the previously provided design can be carried out. In the calculations made it can be evidenced that there are different areas of steel for the different areas of the slab, having as the most critical area of steel the $28.16 \mathrm{~cm} 2$ value that resembles the area of steel estimated for the entire slab of $0.60 \mathrm{~m}$ thick in general, by those who executed the construction of the work.

For the case of vertical sidewall values of $18.15 \mathrm{~cm}$ were obtained2 steel and the central walls of $14.85 \mathrm{~cm} v a l u e s$ were obtained 2 steel, performing an observation in table 3 which corresponds to the values of steel placed on work, you can see a not very noticeable difference. These variations may have arisen due to errors in the estimation of soil characteristics.

It is recommended to project a sewer of this type, only when the flows are low and the floating material does not generate obstruction in the flow of water, nor undermining its foundation. It is recommended to protect the old sides of the sewer, both upstream and downstream, from the right and left with gabion walls to minimize the impact of erosion and undermining generated by the effect of water velocity on the concrete structure and the ground.

It is recommended to do a risk study and mitigate the effects on the downstream population since a work of this size can cause flooding. A periodic and preventive maintenance plan is recommended in order to protect the useful life of the structure

Mendoza, A. V. P., Viteri, C. G. V., \& Menendez, E. A. M. (2019). Analysis of working conditions to which the triaduct is subjected in Roca Fuerte route - Manta. International Journal of Physical Sciences and Engineering, 3(3), 7-14. https://doi.org/10.29332/ijpse.v3n3.353 


\section{Conclusion}

The investigation allowed to deepen the structural characteristics and their working conditions to which the triaduct is subjected. It was possible to carry out the structural analysis in the SAP2000 program, so it was possible to compare that the design results, that is, that the amounts are similar to those obtained by the study that was obtained with the company that built the triaduct, the which led to the conclusion that the structure is constructed correctly.

It was possible to analyze that those in charge of carrying out and executing the work decided to use a sewer and not a bridge due to cost issues, especially in the foundations, since it can be clearly seen that the ideal work was a bridge.

Acknowledgments

Thanks are made to the student and teachers who have worked to achieve this research. 


\section{References}

Aquini, D. \& Hernández, R. (2004). Concrete bridge construction manual. University of El Salvador, Recovered from: http://ri.ues.edu.sv/id/eprint/2076.

Benjumea, J. Chio, G. \& Maldonado, E. (2010). Structural behavior and design criteria of the extracted bridges: general vision and state of the art. Construction engineering magazine.

Castelló, R. (2016). Masterplan, drainage and internal road project of the "Catalina Norte" lot of Rio Primero. UNC digital registry, Retrieved from: $\underline{h t t p: / / h d l . h a n d l e . n e t / 11086 / 5681 . ~}$

García, C. \& Lorenzo, G. (2011). Hazard factors and indices of avenue waters at crossroads of roads with boulevards: study applied to the southern coastal slope of the Region of Murcia. Bulletin of the Association of Spanish Geographers (57), 195-218.

Guillen, I. (2017). Design for the improvement of the road between Los Caseríos el Amante - Matibamba, José Sabogal district - San Marcos province - Cajamarca department. Institutional digital repository of the César Vallejo University, Recovered from: http://repositorio.ucv.edu.pe/handle/UCV/23094.

Lituma, W. (2014). The terrestrial communication system between the El Triunfo Arajuno road crossing to the San Vicente de Villano commune, El Triunfo parish, Pastaza canton, Pastaza province and its influence on the quality of life of the inhabitants. Repository Technical University of Ambato, Recovered from: http://repositorio.uta.edu.ec/handle/123456789/8315.

MTOP (2013). Standard for studies and road designs. NEVI-12, V. 2. Ministry of Transportation and Public Works

Rodríguez, A. (2014). AASHTO specifications for the design of bridges by the LRFD method. ASSTHO - LRFD, p. 27.

Santos, A. (2015). Application of the technique of ground injection by hydraulic fracturing to bridge foundations in circumstances of special difficulty. Polytechnic University of Madrid, Recovered from: http://oa.upm.es/36535/1/ANTONIO SANTOS ESCOBAR.pdf.

Vente Chow, Maidment, D. \& Mays, L. (1994). Applied Hydrology Mc Graw Hill

Yepes, V. (2017). The bridge concept. Polytechnic University of Valencia, Recovered from: https://victoryepes.blogs.upv.es/2017/09/13/el-concepto-de-puente/.

Mendoza, A. V. P., Viteri, C. G. V., \& Menendez, E. A. M. (2019). Analysis of working conditions to which the triaduct is subjected in Roca Fuerte route - Manta. International Journal of Physical Sciences and Engineering, 3(3), 7-14. https://doi.org/10.29332/ijpse.v3n3.353 


\section{Biography of Authors}

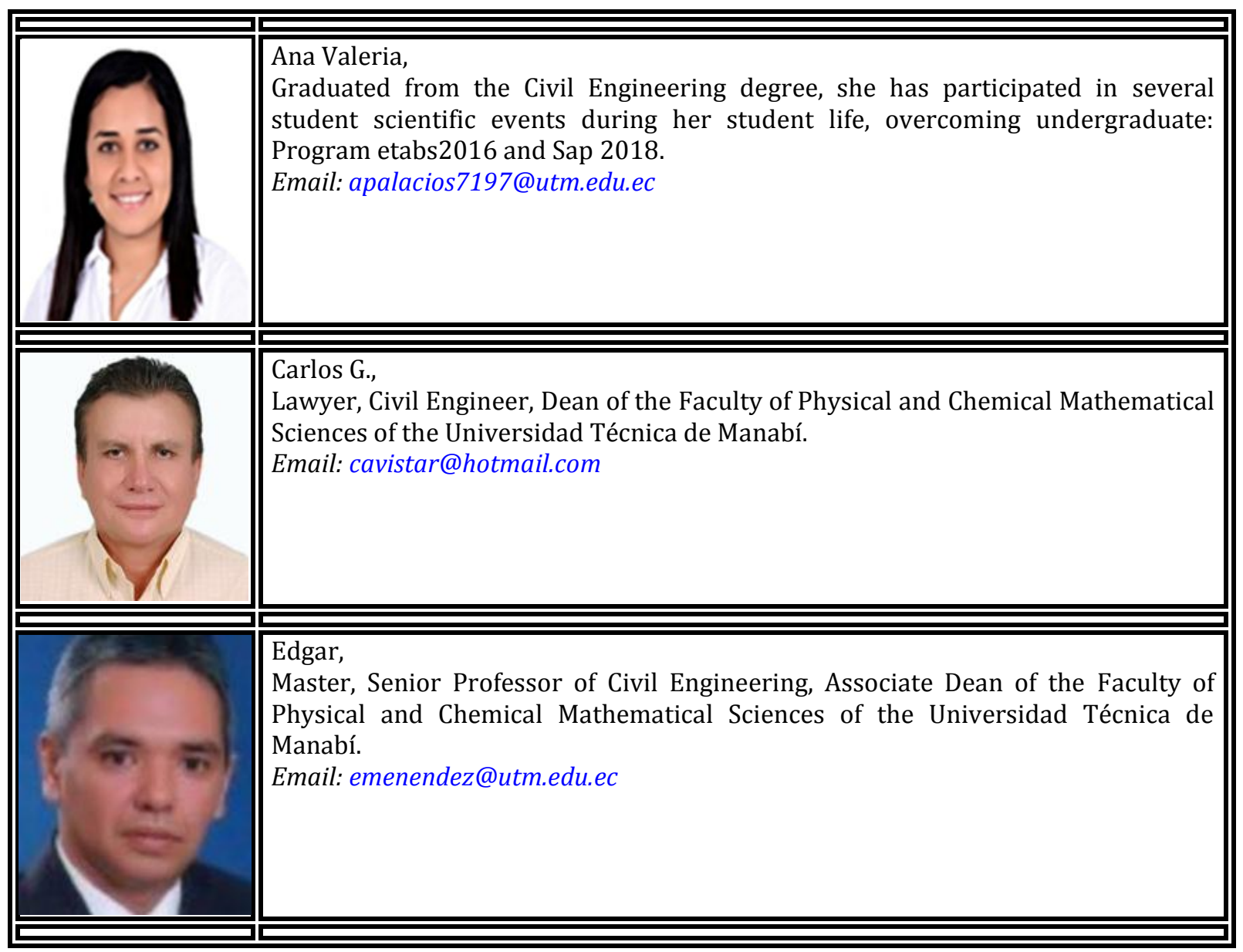

